\title{
PHOTOLUMINESCENCE AND DOUBLE-CRYSTAL X-RAY STUDY OF InGaAs/InP: EFFECT OF RARE EARTH (DYSPROSIUM) ADDITION DURING LIQUID PHASE EPITAXIAL GROWTH*
}

\author{
B. PödöR, L. Csontos, K. Somogyi \\ Research Institute for Technical Physics of the Hungarian Academy of Sciences \\ P.O.B. 76, 1325 Budapest, Hungary \\ AND D. VignaUd \\ U.S.T. Lille Laboratoire de Structure et Propriétés de l'Etat Solide \\ URA 234 CNRS Bât. C6 \\ 59655 Villeneuve d'Ascq, Cédex, France

\begin{abstract}
High purity $\operatorname{In}_{0.53} \mathrm{Ga}_{0.47}$ As layers were grown on semi-insulating $\mathrm{InP}: \mathrm{Fe}$ substrates by liquid phase epitaxy by adding small amounts of dysprosium (rare earth) to the melt. Hall effect and photoluminescence measurements showed that the addition of Dy strongly reduced the carrier and residual donor concentration, with a concurrent shift of the excitonic luminescence toward higher energies. The observed effects are ascribed to the gettering of residual donor impurities in the melt by Dy, as well as to the effects of possible incorporation of $D y$ into the grown layers.
\end{abstract}

PACS numbers: 78.55.-m, 72.80.Ey

\section{Introduction}

High purity $\mathrm{In}_{0.53} \mathrm{Ga}_{0.47} \mathrm{As}$ layers were grown on semi-insulating InP substrates by liquid phase epitaxy (LPE). High purity was achieved by adding small amounts of rare earth element (REE) dysprosium (Dy) to the melt. REEs form stable compounds with the donor type impurities which are insoluble in the indium melt, thus preventing their incorporation into the grown layers, leading to the suppression of the unintentional residual donor impurities (or gettering effect) [1-3]. REEs can also be incorporated into the lattice, which might lead to the modification of mismatch strains in the heteroepitaxial layer.

*This work is supported from grants No. OTKA/12037 and No. OTKA/14094 from the Hungarian National Research Foundation and from grant No. CP93:8252 from the EC COPERNICUS Project. 
The aim of this work was to investigate the effect of the variation of the Dy doping level on the properties of InGaAs layers on InP, in order to obtain a better understanding of the underlying mechanisms. A more detailed account will be published elsewhere [4].

\section{Liquid phase epitaxial layer growth and characterization}

LPE In In $_{0.53} \mathrm{Ga}_{0.47} \mathrm{As}$ layers were grown on (100) oriented semi-insulating InP:Fe substrates with various amounts of $\mathrm{Dy}$ (up to 0.15 atomic per cent) added to the melt, in a conventional multiple-well horizontal graphite slider boat and quartz tube epitaxial growth apparatus in $\mathrm{Pd}$-purified flowing hydrogen atmosphere [5]. Before the growth the InP substrates were etched in 2 per cent Br-methanol for 2 minutes.

The source materials were $6 \mathrm{~N}$ In and Bridgman and Czochralski grown GaAs and InAs single crystals $\left(n \approx 10^{16} \mathrm{~cm}^{-3}\right)$. The atomic fractions of the growth solutions were $x_{\mathrm{As}}=0.051$ and $x_{\mathrm{Ga}}=0.022$, respectively, calculated for the liq-

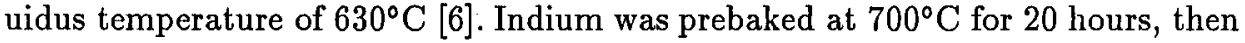
weighed InAs and GaAs were added to the melt to form the growth solution, which was baked again at $700^{\circ} \mathrm{C}$ for $40-64$ hours. Then Dy was added and the melt was baked for the third time at $690-700^{\circ} \mathrm{C}$ for 20 hours. The $\operatorname{In}_{0.53} \mathrm{Ga}_{0.47} \mathrm{As}$ layers were grown at $625^{\circ} \mathrm{C}$ by using a step cooling technique with $5^{\circ} \mathrm{C}$ supercooling. 5-6 minutes of growth resulted in 3-5 $\mu \mathrm{m}$ thick layers.

The grown layers were characterized by various methods. Double-crystal $\mathrm{X}$-ray diffraction (DCXRD) was performed on the layers and the (004) reflection rocking curves were recorded. Hall effect and conductivity measurements were performed using the Van der Pauw technique at $300 \mathrm{~K}$ and $77 \mathrm{~K}$. Near band edge photoluminescence (PL) spectra, excited by a $\mathrm{Kr}$ ion laser, were recorded at $4.4 \mathrm{~K}$, using a $1 \mathrm{~m}$ monochromator coupled to a cooled Ge detector [7].

\section{Results and discussion}

The relaxed lattice mismatch was obtained from the DCXRD data with corrections for the tetragonal distortion [8]. The grown $\operatorname{In}_{0.53} \mathrm{Ga}_{0.47} \mathrm{As}$ layers were slightly in compression (In-rich side of the growth) (cf. Table), and the lattice mismatch decreased with an increasing amount of Dy added to the melt.

Figure 1 presents the $300 \mathrm{~K}$ carrier concentration data versus the Dy concentration in the melt (cf. also Table). With an increasing amount of Dy the electron concentration in the layers decreased from about $1 \times 10^{17} \mathrm{~cm}^{-3}$ when no Dy was added, to $(2-5) \times 10^{16} \mathrm{~cm}^{-3}$ for $0.005-0.01$ atomic percent Dy, while $0.02-0.05$ atomic percent added Dy decreased it further to $(2-10) \times 10^{14} \mathrm{~cm}^{-3}$, then resulted in a conversion to $p$-type with a hole concentration of $(2-20) \times 10^{14} \mathrm{~cm}^{-3}$ above 0.03-0.07 atomic per cent Dy. The behaviour in this range, however, is influenced by the exact value of the residual acceptor concentration.

Using the measured mobilities (cf. Table), the concentration of ionized donors $\left(N_{\mathrm{D}}\right)$ and acceptors $\left(N_{\mathrm{A}}\right)$ was estimated from the appropriate theoretical curves $[9,10]$, allowing the separate determination of $N_{\mathrm{D}}$ and $N_{\mathrm{A}}$ for each layer (see Table). The concentration of uncontrolled background acceptors remained roughly 


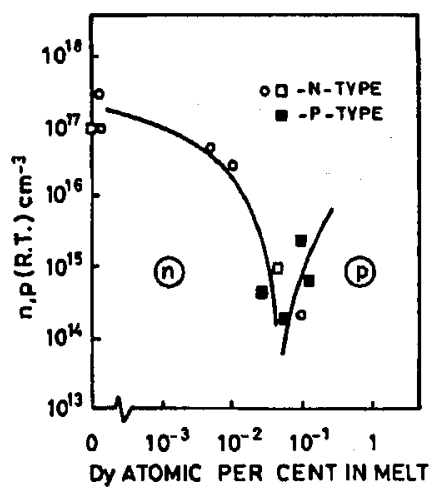

Fig. 1. $300 \mathrm{~K}$ carrier concentration versus the Dy content in the melt.

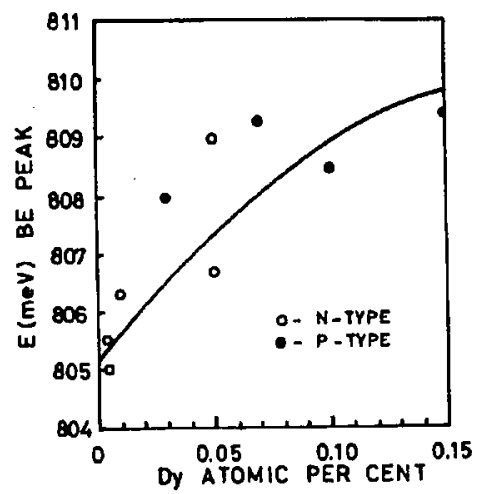

Fig. 2. $4.4 \mathrm{~K}$ bound exciton energy versus the Dy content in the melt.

TABLE

Relaxed lattice mismatch, room temperature carrier concentration and mobility, and bound exciton peak positions at $4.4 \mathrm{~K}$ for representative InGaAs layers.

\begin{tabular}{l|l|l|c|c|c|c|c}
\hline Sample & $\begin{array}{l}\text { Dy atomic } \\
\text { per cent }\end{array}$ & $\begin{array}{l}\mathrm{d} a / a \\
{\left[10^{-4}\right]}\end{array}$ & $\begin{array}{c}n \text { or } p \\
{\left[\mathrm{~cm}^{-3}\right]}\end{array}$ & $\begin{array}{c}\mu \\
{\left[\mathrm{cm}^{2} /(\mathrm{V} \mathrm{s})\right]}\end{array}$ & $\begin{array}{c}N_{\mathrm{D}} \\
{\left[\mathrm{cm}^{-3}\right]}\end{array}$ & $\begin{array}{c}N_{\mathrm{A}} \\
{\left[\mathrm{cm}^{-3}\right]}\end{array}$ & $\begin{array}{c}\mathrm{BE} \\
{\left[\mathrm{meV}^{-3}\right.}\end{array}$ \\
\hline 1115 & none & 4.9 & $(\mathrm{n}) 1.0 \times 10^{17}$ & 7470 & $1.1 \times 10^{17}$ & $1 \times 10^{16}$ & 801.1 \\
0215 & 0.005 & 1.79 & $(\mathrm{n}) 5.6 \times 10^{16}$ & 7360 & $8.8 \times 10^{16}$ & $3.2 \times 10^{16}$ & 805.0 \\
0225 & 0.01 & 2.32 & $(\mathrm{n}) 2.8 \times 10^{16}$ & 8200 & $4.5 \times 10^{16}$ & $1.7 \times 10^{16}$ & 806.3 \\
1111 & 0.05 & 2.3 & $(\mathrm{n}) 1.0 \times 10^{15}$ & 9960 & $7.5 \times 10^{15}$ & $6.5 \times 10^{15}$ & 809.0 \\
$1117 \mathrm{~A}$ & 0.07 & 1.6 & $(\mathrm{p}) 3 \times 10^{14}$ & 180 & - & - & 809.3 \\
0303 & 0.10 & 1.31 & $(\mathrm{n}) 2.1 \times 10^{14}$ & 9450 & $1 \times 10^{16}$ & $1 \times 10^{16}$ & 805.8 \\
1112 & 0.10 & 1.6 & $(\mathrm{p}) 2.5 \times 10^{15}$ & 210 & - & - & 808.5 \\
$1117 \mathrm{~B}$ & 0.15 & 0.95 & $(\mathrm{p}) 7.5 \times 10^{15}$ & 175 & - & 809.0
\end{tabular}


constant at the level of (1-3) $\times 10^{16} \mathrm{~cm}^{-3}$. Up to about $0.01-0.02$ atomic per cent Dy in the melt the donor concentration decreased roughly in proportion with the Dy content, then reached the level of uncontrolled acceptor concentrations, resulting in closely compensated $n$-type and for a further increase in the amount of $D y$, in compensated $p$-type layers.

At $4.4 \mathrm{~K}$ the PL spectra consisted of three bands, a bound exciton (BE) line at $800-809 \mathrm{meV}$, a donor-to-acceptor band at about $786 \mathrm{meV}$ assigned to $\mathrm{Si}$ on As-site acceptors, and a band assigned to the phonon replica of the donor-to-acceptor band at about $754 \mathrm{meV}$. The positions of the BE lines shifted to higher energy with increasing amount of Dy added to the melt during the crystal growth (see Fig. 2 and Table). The half-width of the BE line decreased strongly with increasing Dy concentrations for low concentrations of Dy, and saturated above about 0.03 atomic per cent $D y$, at a value of $3-3.5 \mathrm{meV}$ which is comparable with the best reported values for layers grown by LPE [11].

\section{Summary}

In conclusion, the above experimental observations, i.e. the decrease in lattice mismatch and in donor impurity concentration, and the upward shift of the bound exciton line toward values corresponding to lattice match as well as the decrease in the width of the excitonic line with increasing amount of Dy in the melt can be satisfactorily interpreted by the effect of gettering of unintentional donor impurities in the melt by Dy, as well as by the effect of strain modification in the layers due to the incorporation of Dy.

\section{References}

[1] N.T. Bagraev, L.S. Vlasenko, K.A. Gatsoev, A.T. Gorelonok, A.V. Kamatin, V.V. Mamutin, B.V. Pushnyi, V.K. Tibilov, Yu.P. Tolparov, A.E. Shubin, Fiz: Tekh. Poluprovodn. 18, 83 (1984) [Sov. Phys.-Semicond. 18, 49 (1984)].

[2] A.T. Gorelenok, V.G. Gruzdov, R. Kumar, W.W. Mamutin, A.T. Polianskaya, I.G. Saveliev, Yu.W. Shmarcev, Fiz. Tekh. Poluprovodn. 22, 35 (1988) [Sov. Phys.-Semicond. 22, 28 (1988)].

[3] A. Kumar, D.N. Bose, Mater. Sci. Eng. B 12, 389 (1992).

[4] L. Csontos, D. Vignaud, B. Pödör, K. Somogyi, to be published.

[5] J. Pfeifer, L. Andor, L. Csontos, Z. Labadi, K. Wlodarczyk, in: Proc. 3rd European Conf. on Crystal Growth, Budapest 1991, Ed. A. Lörinczy, Part II, Trans Tech. Publ., Zürich 1991, p. 496.

[6] K. Sakai, Y. Matsushima, S. Akiba, T. Yamamoto, Jpn. J. Appl. Phys. 18, 1009 (1979).

[7] D. Vignaud, X. Wallart, F. Mollot, J. Appl. Phys., in press.

[8] I.C. Bassignana, C.J. Miner, N. Puetz, J. Appl. Phys. 65, 4299 (1989).

[9] Y. Takeda, in: GaInAsP Alloy Semiconductors, Ed. T.P. Pearsall, Wiley, New York 1982, Ch. 9.

[10] L.F. Eastman, in: Properties of Lattice Matched and Strained InGaAs, Ed. P. Bhattacharya, INSPEC, London 1993, Ch. 4.1.

[11] D. Bimberg, B. Srocka, in: Properties of Lattice Matched and Strained InGaAs, Ed. P. Bhattacharya, INSPEC, London 1993, Ch. 6.1. 